http://jmscr.igmpublication.org/home/

ISSN (e)-2347-176x ISSN (p) 2455-0450

crossref DOI: https://dx.doi.org/10.18535/jmscr/v7i8.42

Journal Of Medical Science And Clinical Research

\title{
Inverted Follicular Keratosis: A Case Report
}

\author{
Authors \\ Samriti Sood ${ }^{1}$, Saru Thakur ${ }^{2 *}$, Mudita Gupta ${ }^{3}$, Reena Kumari Sharma ${ }^{4}$ \\ ${ }^{1,2}$ Post graduate student, ${ }^{3}$ Assistant Professor, ${ }^{4}$ Senior Resident, \\ Dept. of Dermatology, Venereology and Leprosy, Indira Gandhi Medical College, Shimla \\ *Corresponding Author \\ Saru Thakur \\ Dept. of Dermatology, Leprosy and Venereology, Indira Gandhi Medical College, Shimla,
} Himachal Pradesh, India

\begin{abstract}
Inverted follicular keratosis is a rare tumor arising from the infundibulum of the hair follicle and considered to be a variant of seborrheic keratosis. It presents as a erythematous nodular lesion over head and neck more commonly in middle aged males. A case of inverted follicular keratosis is being reported in a 45 year old male.
\end{abstract}

Keywords: inverted, follicular, infundibulum, nodular.

\section{Introduction}

Inverted follicular keratosis (IFK) is a benign tumor originating from follicular infundibulum characterised by a solitary nodular lesion in middle to old aged individuals on head and neck. It is considered to be a variant of seborrheic keratosis $^{(1)}$. Here we report a case of 45 years old male with a solitary nodular lesion on the scalp in whom a high clinical suspicion on the part of attending dermatologist lead to the diagnosis.

\section{Case Report}

A 45 years male presented to the clinic with a history of slow growing asymptomatic lesion on the scalp from last 4 years. He was averagely built, farmer by occupation. There was no significant past, family and medical history. General physical and systemic examination was done and was found to be within normal limits.
On mucocutaneous examination, there was a welldefined erythematous pedunculated nodule of size $2 \times 2 \mathrm{cms}$ approximately on the parietal area of scalp (Figure 1).

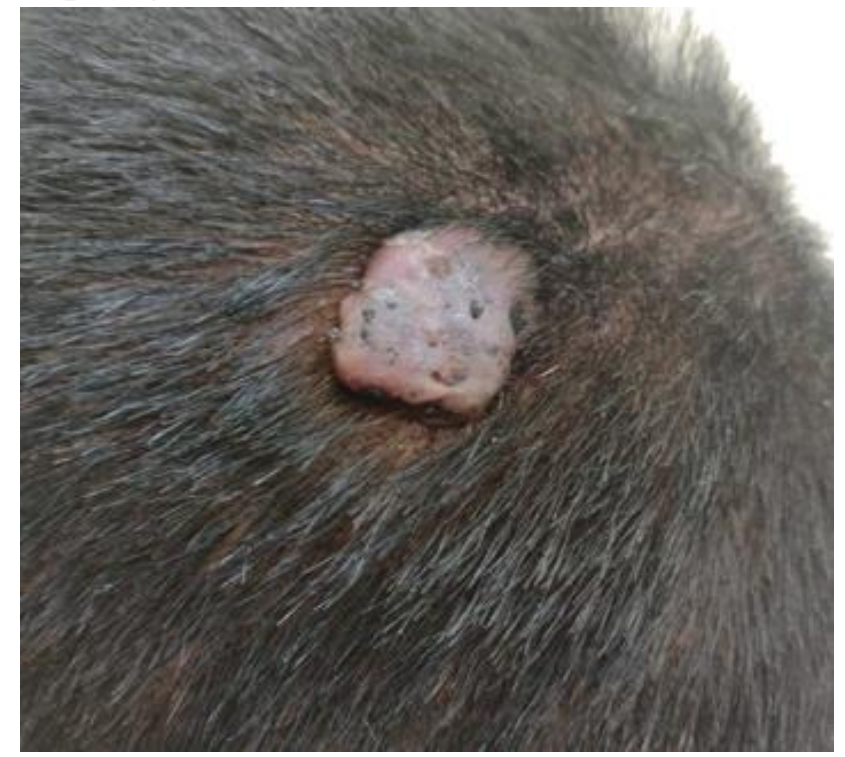

Figure 1: Erythematous pedunculated nodule seen with follicular plugging over the scalp. 
The surface of the nodule was rough with follicular plugging and scaling. Multiple dermatosis papulosa nigra were present on face and neck. There was no significant lymphadenopathy in the patient. The provisional diagnosis of inverted follicular keratosis, trichilemmal cyst and basal cell carcinoma was kept.

Excision of the lesion was done and sent for histopathological examination. The histology revealed a hyperparakeratotic endophytic growth, with tumor cells arranged in large lobules or longitudinal strands projecting into the dermis. Presence of squamous cells arranged in a whorled pattern known as squamous eddies were also seen. However, no cell invasion in the dermis was seen distinguishing it from the squamous cell carcinoma. The patient was diagnosed as inverted follicular keratosis based on the clinical and histopathological findings.

\section{Discussion}

Inverted follicular keratosis is a rare benign tumor of follicular origin. It is considered to be a subtype of seborrheic keratosis due to their histopathological resemblance. ${ }^{(1,2)}$ However, some authors believe that inverted follicular keratosis is a different entity. IFK is commonly seen in middle to old age males with head and neck as the most common site in $90 \%{ }^{(3)}$ as seen in our case. However, it is not as common a classic seborrheic keratosis. The etiopathogenesis is unknown but role of human papilloma virus (HPV) has been proposed. HPV is found to infect the infundibular region of the hair follicle resulting in reactive proliferation of epithelial cells. ${ }^{(4)}$ IFK is the most superficial tumor of the hair follicle, arising as the result of irritation. A rare association with cowden syndrome has been observed, where patient presented with multiple acral keratosis and inverted follicular keratosis. ${ }^{(5)}$ No advanced investigations for HPV could be performed in our case.

Inverted follicular keratosis is a histopathological diagnosis requiring high clinical suspicion.
Histologically it is characterized by large lobules extending into the dermis made up squamous cells in a whorled pattern at the centre known as squamous eddies and of basaloid cells at the periphery Additionally, hyperkeratosis and parakeratosis with occasional keratinous plugs can be seen. ${ }^{(6)}$ Inverted follicular keratosis needs to be differentiated from irritated seborrheic keratosis that may mimics both benign and malignant conditions.

Surgical excision is the treatment of choice for management of inverted follicular keratosis with no recurrences. Other modalities tried are topical $5 \%$ imiquimod cream with complete regression of lesion after 2 months of application. ${ }^{(7)}$

\section{Conclusion}

Inverted follicular keratosis is a rare benign tumor requiring high clinical suspicion on the part of attending dermatologist. Histopathological examination is diagnostic and surgical excision is considered the treatment of choice.

\section{Conflict of Interest: Nil}

Sources of Support and Sponsorship: Nil

\section{Sources of support: Nil}

\section{References}

1. Mehregan AH. Inverted follicular keratosis is a distinct follicular tumor. Am $\mathbf{J}$ Dermatopathol 1983; 5:467-70.

2. Spielvogel RL, Austin C, Ackerman AB. Inverted follicular keratosis is not a specific keratosis but a verruca vulgaris (or seborrheic keratosis) with squamous eddies. Am J Dermatopathol 1983; 5:42742.

3. Armengot-Carbo M, Abrego A, Gonzalez $\mathrm{T}$, Alarcon I, Alos L, Carrera C, et al. Inverted follicular keratosis: Dermoscopic and reflectance confocal microscopic features. Dermatology 2013; 227:62-6.

4. Amoli FA, Alain A, Heidari AB, Jahanzad I. Detection of human papillomavirus 
infection in inverted follicular keratosis

lesions of the eyelid by immunohistochemistry method. Acta Med Iran 2009; 47:436-8.

5. Larumbe A, Iglesias EM, IIIarramendi JJ, Córdoba A, Gállego M. Acral keratoses and inverted follicular keratosis presenting Cowden disease. Actas Dermosifiliogr 2007; 98:425-9.

6. Weedon D. Tumors of cutaneous appendages. In: Weedon D, editor. Weedon's Skin Pathology. $3^{\text {rd }}$ ed. Amsterdam: Elsevier; 2010. p. 765-6.

7. Karadag AS, Ozlu E, Uzuncakmak TK, Akdeniz N, Cobanoglu B, Oman B. Inverted follicular keratosis successfully treated with imiquimod. Indian Dermatol Online J 2016; 7:177-9. 